\title{
The Variation of the Intensity, Height, and Size of Precipitation Systems with EI Niño-Southern Oscillation in the Tropics and Subtropics
}

\author{
Nana LiU, Chuntao LiU, and Thomas Lavigne \\ Department of Physical and Environmental Sciences, Texas A\&M University, Corpus Christi, Texas
}

(Manuscript received 8 November 2018, in final form 13 April 2019)

\begin{abstract}
A 16-yr (1998-2013) Tropical Rainfall Measuring Mission (TRMM) Precipitation Feature (PF) database is used to examine the impacts of El Niño-Southern Oscillation (ENSO) on the characteristics of precipitation systems in the tropics and subtropics. Noticeable differences in the fractions of deep systems (20-dB $Z$ radar echo tops greater than $10 \mathrm{~km}$ ) and mesoscale convective systems (MCSs) (an area greater than $2000 \mathrm{~km}^{2}$ ) between different phases of ENSO are found over specific regions, including the central Pacific (CPACI), the western Maritime Continent (WMC), the eastern Maritime Continent (EMC), Gulf of Mexico (GM), Argentina (ARGEN), and Australia (AUS). The coefficients of determination $R^{2}$ between the multivariate ENSO index (MEI) and the population fractions of deep convection and MCSs are analyzed seasonally over these regions. The responses from these precipitation systems to ENSO are found to be more pronounced in the winter half-year than in the summer half-year. An increase of rainfall during El Niño periods over the CPACI, GM, and ARGEN is found to be associated with more precipitation events and a higher fraction of intense, deep, and large precipitation systems. AUS has fewer precipitation events and a higher fraction of shallow and small precipitation systems during El Niño conditions. Both EMC and WMC have a higher fraction of MCSs during La Niña than El Niño conditions. The EMC observes a higher fraction of deep convection during La Niña conditions. However, the WMC has a higher fraction of deep convection during El Niño conditions, possibly related to the effect of the Indian Ocean dipole.
\end{abstract}

\section{Introduction}

As a dominant coupled mode of tropical variability on interannual time scales (Rasmusson and Carpenter 1982), El Niño-Southern Oscillation (ENSO) has been accounted for in climate anomalies since the early years of the last century (Walker 1925). The effect of extreme phases of ENSO on the precipitation variation is well documented, especially over the equatorial Pacific. Knowledge of ENSO-precipitation over the tropical Pacific spawned many efforts to document the role of ENSO in the climate anomaly over other regions. For example, Rasmusson and Carpenter (1983) showed the ENSO events may impact the Asian-Australian monsoon, and these atmosphere circulation changes during ENSO events could have an influence on the storm frequency and intensity (Williams 2005). Leigh and Kuhnel (2001) suggested that severe thunderstorms in Australia (AUS) are related to certain ENSO cycles (Leigh and Kuhnel 2001; Yeo 2005). A number of

\footnotetext{
Corresponding author: Nana Liu, nliu@islander.tamucc.edu
}

studies also established that North America contains a significant ENSO signal in extreme precipitation (e.g., Gershunov 1998; Cayan et al. 1999; Jong et al. 2016).

Unprecedented efforts have also been put into the examination of which characteristics of precipitationconvection best correspond to the precipitation variation over different regions. Zolman et al. (2000) presents that the tropical anomalous precipitation is not explained by the area distribution and median intensity of tropical mesoscale convective systems (MCSs), using 2 years of $85-\mathrm{GHz}$ brightness temperature data of the Special Sensor Microwave Imager (SSM/I). Mohr et al. (2009) indicated the stability of area and intensity in the CFDs of precipitation systems during different phases of ENSO years in West Africa and the western Pacific tropical cyclone basin. Over the warm pool region, Mapes and Houze (1993) observed a noticeable difference in the cumulative fraction of cold clouds $(<235 \mathrm{~K})$ between warm and cold ENSO events, based on the analysis of IR cloud clusters. In addition, the size distribution of 208- and 198-K cloud clusters indicates that cloud clusters are dominated by small clusters, with $50 \%$ 


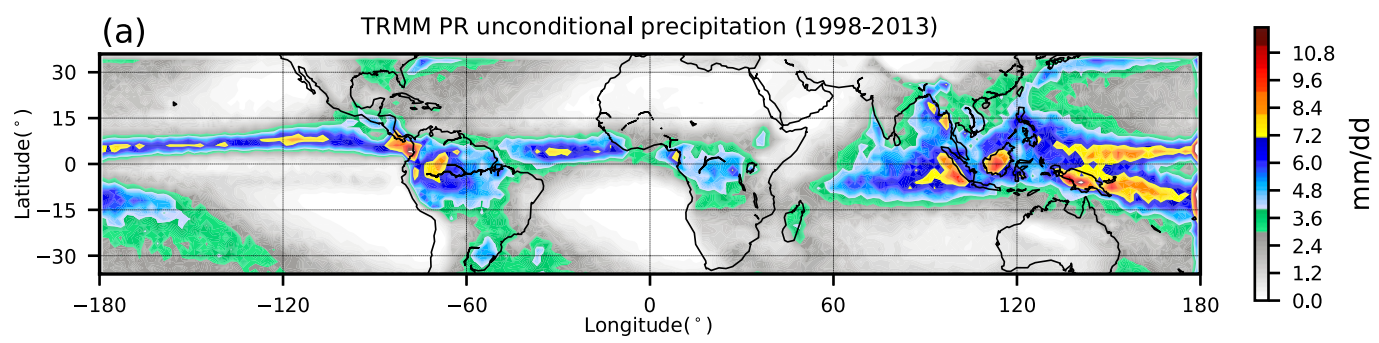

(b) Difference of unconditional precipitation (EI Niño - La Niña) (1998-2013)

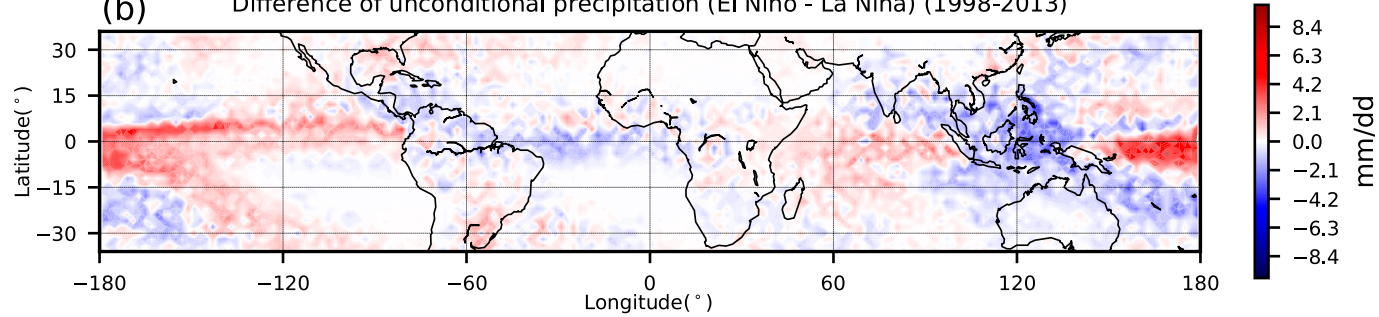

(c)

Precipitation anomaly (1998-2013)

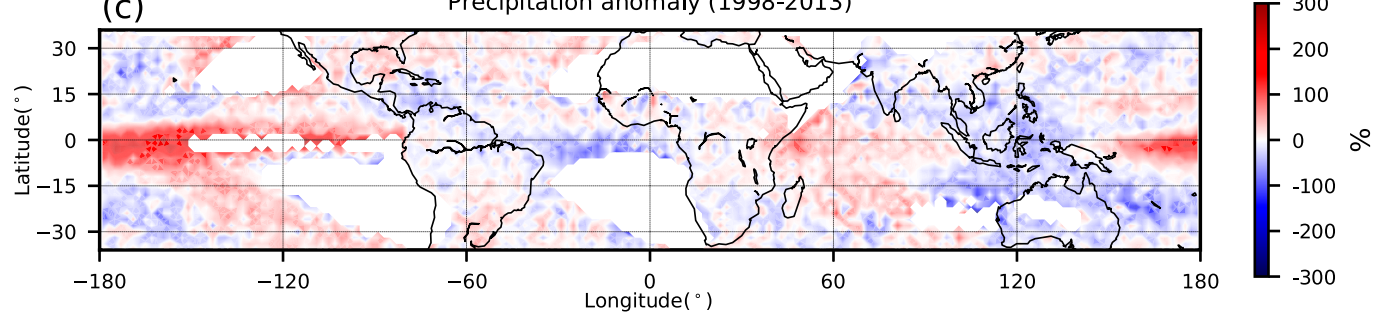

FIG. 1. Climatology of unconditional precipitation observed by TRMM PR during 1998-2013: (a) unconditional precipitation $\left(\mathrm{mm} \mathrm{day}^{-1}\right)$, (b) difference of unconditional precipitation between El Niño and La Niña periods, and (c) normalized difference between El Niño and La Niña [(b) divided by (a)]. Boxes with unconditional precipitation $<0.5 \mathrm{~mm} \mathrm{day}^{-1}$ are blank. The unconditional precipitation is calculated using the TRMM $2 \mathrm{~A} 25$ near-surface precipitation product. MEIs (Fig. 2) have been used to separate El Niño and La Niña conditions (see details in section $2 b)$.

$(80 \%)$ of clusters smaller than $300(1000) \mathrm{km}^{2}$. Therefore, the area distribution of clusters is not always revealing of the relative importance of cluster with various sizes, especially with a limited sample.

Is ENSO-related anomalous precipitation explained by more precipitation events, or larger and/or more intense precipitation events? The answer to this question is still not clear. This study expands previous studies by investigating which characteristic of precipitation systems best corresponds to the precipitation variation over different regions, with a consistent methodology and dataset. The coverage of the Tropical Rainfall Measuring Mission (TRMM) allows the investigation of the characteristics of precipitation across the tropics and subtropics $\left(35^{\circ} \mathrm{N}-35^{\circ} \mathrm{S}\right)$ from the launch of the satellite in November 1997 to mid-2014 (Kummerow et al. 1998). Launched in early 2014, the Global Precipitation Measurement Core Observatory satellite (Hou et al. 2014), as the next generation of TRMM, has extended the studies of precipitation to the mid- and high latitudes (Liu and Zipser 2015). However, given the short period observations from GPM and the uncertainty by combining observations from different satellites, only the long time period observations from TRMM are used in this study. The ability of the Precipitation Radar (PR) on board TRMM to see the three-dimensional structure of the precipitation at high horizontal and vertical resolution provides a unique vision of the ENSO-precipitation relationship.

The climatology of unconditional precipitation observed by the TRMM PR in Fig. 1a shows a robust statistics of precipitation using 16 years of observations. The unconditional precipitation is defined as total precipitation accumulation, including both precipitation and nonprecipitation time periods, and calculated by dividing the total PR-detected precipitation with the total PR samples. Using 16 years of TRMM records, we are able to subset the samples and create robust statistics of precipitation under strong warm and cold ENSO phases (Fig. 2; details in section 2). Figure 1b shows the difference of precipitation between the warm and cold phases of ENSO. The results follow the well-documented 


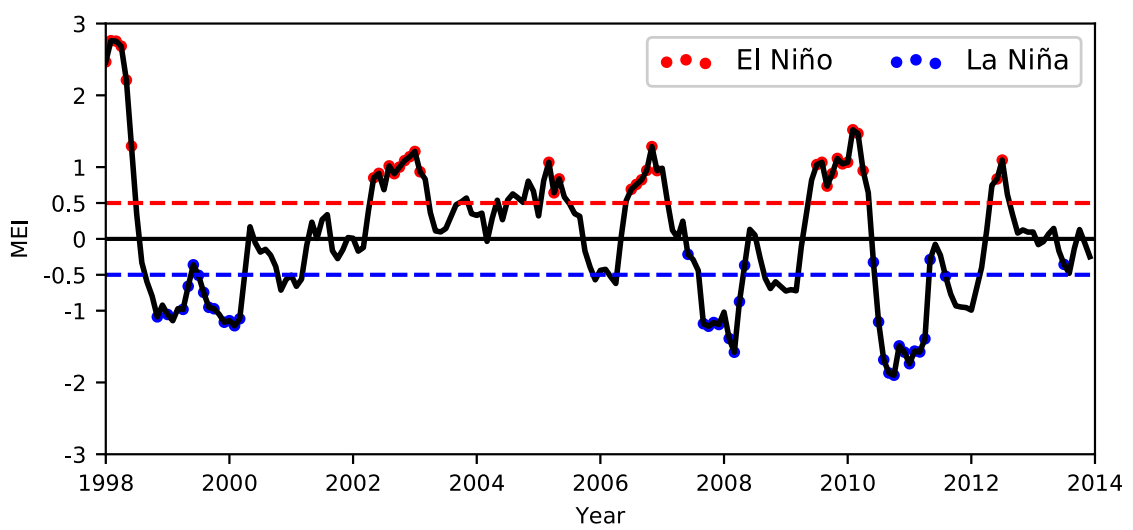

FIG. 2. Time series of MEI during 1998-2013. Red dots are El Niño months, blue dots are La Niña months, and red and blue dashed lines indicate MEI $=0.5$ and -0.5 , respectively.

ENSO-related anomalous precipitation (Ropelewski and Halpert 1987; Kiladis and Diaz 1989; Dai and Wigley 2000; Lyon and Barnston 2005; Yang and DelSole 2012), with enhanced precipitation over the eastern and central $\mathrm{Pa}$ cific, and reduced rainfall over the Maritime Continent during El Niño years and vice versa during La Niña years. The effects on the anomaly of rainfall in the Indian Ocean and Atlantic Ocean are less pronounced than the tropical Pacific and Maritime Continent. The fractional anomaly in total precipitation (Fig. 1c) shows almost 3 times the precipitation over the central Pacific (CPACI) in the warm phase versus cold phase of ENSO periods (Fig. 1c). Zolman et al. (2000) also show that the number of MCSs in winter (summer) over the equatorial central Pacific during El Niño is 4 (3) times that during La Niña year.

The goal of this study is to revisit the question of whether ENSO-related anomalous precipitation is associated with the variation of the intensity, area, and heights of convective systems, with much larger samples than previous studies. This study describes the data and methodology in section 2 . Section 3 presents the effect of ENSO as a potential factor for the characteristics of convective systems. Finally, the conclusions and a summary are provided in section 4 .

\section{Data and methods}

\section{a. TRMM PF dataset}

Our effort is to extend the understanding of anomalous precipitation through the analysis of the characteristics of precipitation systems based on the use of long-term records (1998-2013) of TRMM rainfall products obtained from the PR and the TRMM Microwave Imager (TMI). The data source is obtained from the precipitation features (PFs) (Nesbitt et al. 2000; Liu et al. 2008), derived from the TRMM, version 7, rainfall products. PFs are defined by grouping contiguous pixels with near surface rainfall derived from the TRMM PR (Iguchi et al. 2000, 2009). Various parameters are used in this study to explore the properties of precipitation systems, including PF area, the maximum height of 20$\mathrm{dBZ}$ radar reflectivity (MAXHT20), and the minimum $85-\mathrm{GHz}$ polarization corrected temperature (Spencer et al. 1989; MIN85PCT). Directly associated with the ice scattering signature in the column, $85-\mathrm{GHz}$ PCT have been commonly used as a proxy of convective intensity (e.g., Cecil and Zipser 1999; Nesbitt and Zipser 2003; Liu and Zipser 2005; Mohr et al. 2009). Therefore, the minimum $85-\mathrm{GHz}$ PCT of each PF is used to examine the different intensity of convective systems under warm and cold phases of ENSO. The general size distribution of cloud clusters, dominated by small clusters, inspires us to pay particular attention to the heavy-tailed nature of the precipitation from the deepest and the largest systems. Deep convective systems are defined as PFs with the MAXHT20 greater than $10 \mathrm{~km}$. With only $10 \%-20 \%$ of the population but more than $70 \%$ contribution of the rainfall (Mohr et al. 1999; Nesbitt et al. 2000), MCSs are defined as PFs with areas greater than $2000 \mathrm{~km}^{2}$. Here, two terms related to the deep/tall or large precipitation systems have also been defined to characterize the properties of precipitation systems in this study. One is occurrence, which is defined as the total pixels of PFs divided by total sampled pixels in the PR swath and multiplied by $100(\%)$. The second term is fraction, which is defined as the number of PFs divided by the total number of PFs for the entire time period and multiplied by 100 (\%). To remove the noise, only PFs with at least four pixels (about $80 \mathrm{~km}^{2}$ ) are used in this analysis.

\section{b. ENSO index}

The variability associated with ENSO is represented by the multivariate ENSO index (MEI) (Wolter and 
Timlin 2011). MEI is defined as the first unrotated principal component of six observed atmosphere-ocean variables (sea level pressure, zonal and meridional components of the surface wind, sea surface temperature, surface air temperature, and total cloud fraction of the sky) over the tropical Pacific $\left(30^{\circ} \mathrm{N}-30^{\circ} \mathrm{S}, 100^{\circ} \mathrm{E}-\right.$ $70^{\circ} \mathrm{W}$ ). Consistent with the past studies (e.g., Kiem and Franks 2001; Andrew et al. 2004; Shrestha and Kostaschuk 2005), months with values greater than +0.5 are considered as El Niño conditions, while months with values less than -0.5 are considered as La Niña conditions (Fig. 2). Because there is uneven number of months determined as El Niño and La Niña in each season during the TRMM era, the direct comparison between the averages of El Niño and La Niña monthly properties would be biased. Therefore, two different approaches have been used to address this. The first approach is used to create the mean properties of precipitation systems:

$$
P=\frac{1}{12} \sum_{n=1}^{12} \frac{\sum p_{n}}{\sum S_{n}},
$$

where $P$ is the mean property of precipitation system, $n$ is the month, $p_{n}$ represents the property of precipitation systems (volumetric rain, number of deep convection, and number of MCSs) in the specific month $n$, and $S_{n}$ is total number of sampled pixels (Figs. 1b,c) or total number of PFs (Figs. 3-6) in month $n$ under El Niño or La Niña conditions. For the following analysis in this study, Fig. 1 and Figs. 3-6 are created using this method.

The second approach is to test which characteristics of convective systems correspond to the variation of precipitation in different phases of ENSO, the three strongest El Niño (red dots) and La Niña (blue dots) years are chosen for each month, totaling 3 years of data, as shown in Fig. 2. It is important to note that May, June, and July did not include 3 years of La Niña conditions of less than -0.5 during the TRMM time span. For these months, the three strongest La Niña years with the lowest MEI values are chosen, and all of these months are negative on MEI, indicating they are still slight La Niña conditions. Another important caveat to note is that this 3-yr compiled dataset of the strongest years of each month is not continuous, and the limited ENSO events during the TRMM time period could possibly affect the results. (Figures 7-12 of the study are produced using this second approach.)

\section{Results}

\section{a. Variation of deep precipitation systems during ENSO}

Figure 3 illustrates the geographical distribution of the fraction of deep precipitation systems with $20-\mathrm{dB} Z$ echo tops exceeding $10 \mathrm{~km}$ over the two phases of ENSO. To create this plot, we divide the numbers of PFs with a maximum height of $20 \mathrm{dBZ}$ greater than $10 \mathrm{~km}$, by the total number of PFs in each $2^{\circ} \times 2^{\circ}$ grid box. In general, the geographical distribution of the fraction of deep convection over these two periods shows a similar spatial correspondence with past studies (Liu and Zipser 2005; Zipser et al. 2006; Liu and Liu 2016). These studies identified that more deep convection are found over land than over ocean, with a preference over some specific regions, such as central Africa, Maritime Continent, and Colombia. There is also a relatively larger fraction of deep convection over the intertropical convergence zone (ITCZ) and tropical Atlantic. To make the comparison of deep convection between the two phases of ENSO, the difference of the fraction of deep convection over these two periods is shown in Fig. 3c. Similar with the anomalous precipitation, there is a larger fraction (e.g., $\sim 2.6 \%$ larger over the central Pacific) of deep convection in the central and eastern tropical Pacific and Indian Oceans during the warm phase in comparison with the cold phase of ENSO. The small variation $(\sim 2.6 \%)$ in the fraction of deep convection could result in $\sim 27 \%$ difference in the rain contribution over the central Pacific. A larger fraction ( $\sim 1.2 \%$ larger) of deep convection, accounting for $\sim 5.5 \%$ higher rain contribution, is found over the western Maritime Continent (WMC: $5^{\circ} \mathrm{S}-5^{\circ} \mathrm{N}, 95^{\circ}-$ $115^{\circ} \mathrm{E}$ ) during $\mathrm{El}$ Niño years than that during La Niña periods. The eastern Maritime Continent (EMC: $0^{\circ}-$ $\left.13^{\circ} \mathrm{N}, 115^{\circ}-135^{\circ} \mathrm{E}\right)$ is found to have a smaller fraction $(\sim 1.3 \%$ smaller $)$ and lower rain contribution $(\sim 3.2 \%$ lower) of deep convection during El Niño periods. Over the areas that are favorable for deep convection, such as North America, Argentina (ARGEN), central Africa, and Colombia, the difference in the fraction of deep convection between these two phases of ENSO is also significant (e.g., $\sim 10.3 \%$ during El Niño periods and $\sim 8.7 \%$ during La Niña periods over ARGEN).

\section{b. Variation of size during ENSO}

Figure 4 presents the geographical distribution of the fraction of MCSs during the two phases of ENSO. The general shapes of the distributions in Fig. 4 follow the well-established pattern by various studies (e.g., Laing and Fritsch 1997; Nesbitt and Zipser 2000; Yuan and Houze 2010), with a tendency of a larger concentration over some particular regions (midlatitude South America, central Africa, south-central United States, and southern China). The larger fraction of MCSs during El Niño conditions than that of during La Niña in the central Pacific is consistent with the anomalous precipitation shown in Fig. 1b. The increase (decrease) of 

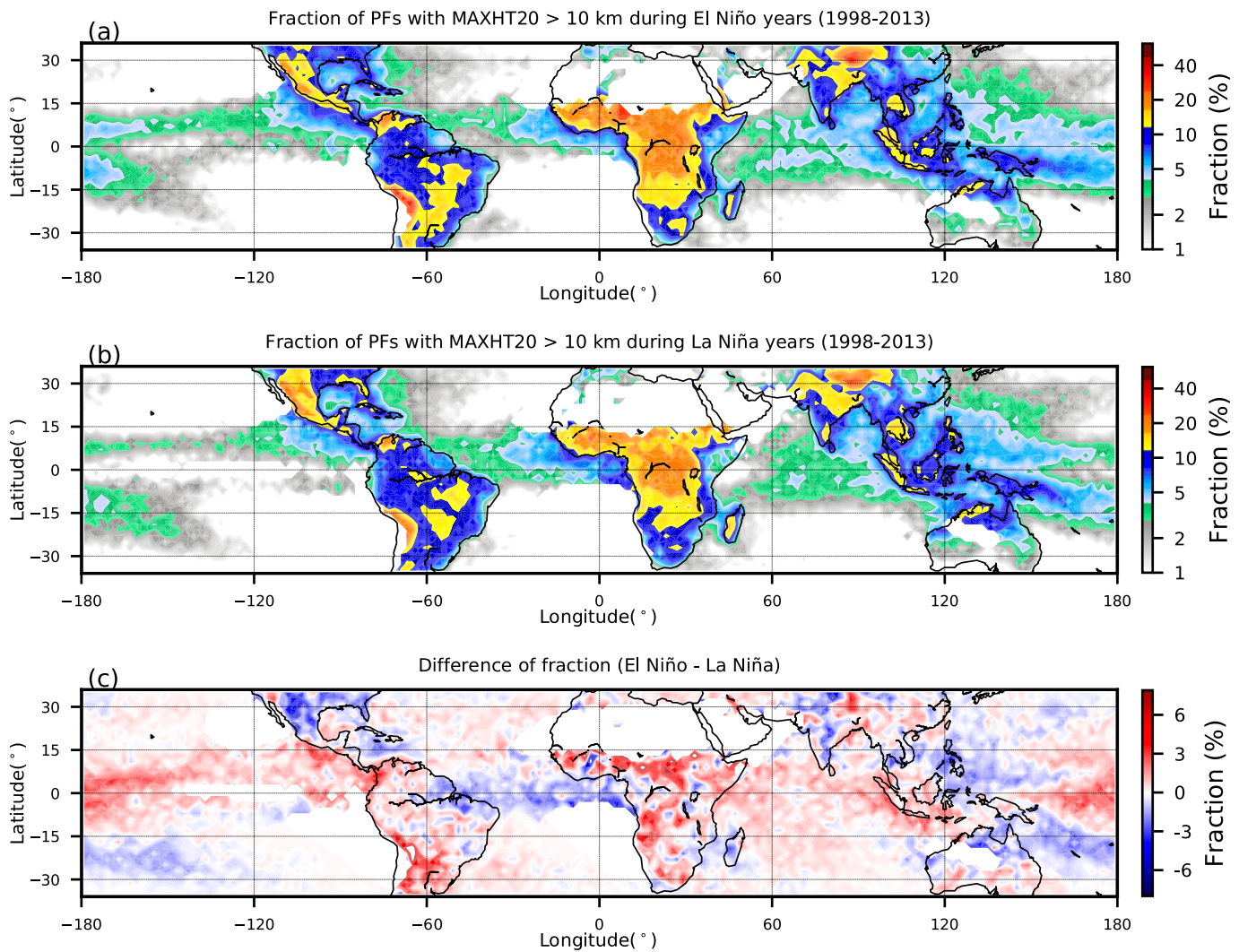

FIG. 3. Fraction of PFs with MAXHT20 $>10 \mathrm{~km}$ during 1998-2013 on a $2^{\circ} \times 2^{\circ}$ grid: (a) during El Niño, (b) during La Niña, and (c) the difference between El Niño and La Niña periods.

the population fraction of MCSs over the WMC under El Niño condition is consistent with the increase (decrease) of precipitation in the region. This indicates that the variation of population of MCSs may play an important role in the precipitation anomaly over the WMC.

\section{c. Geographical correlation between MEI and height/ size of PFs}

To further examine the linkage between ENSO to the size and height of convection, the Pearson correlation ( $r$ value) between the monthly MEI values and the monthly fractions of PFs from deep systems and MCSs are analyzed on a $2^{\circ} \times 2^{\circ}$ grid. As shown in Fig. 5, the effect of ENSO on the heights and size of convective systems over the areas directly linked to ENSO, are more pronounced than those areas with an indirect link. The largest correlation over the tropical Pacific and Maritime Continent provide supportive evidence. Regions of the world with a direct link to ENSO are considered as immediately touching the Pacific Walker circulation region, which extends from the west coast of North America, westward to the Maritime Continent and Southeast Asia (Julian and Chervin 1978). All other regions of the globe that are not directly touching the Pacific Walker circulation region are considered as indirectly linked to ENSO. The areas with the largest correlation of ENSO variability to both storm height and horizontal size, lie inside the region defined as having a direct link to ENSO variability. The positive correlation over the WMC is consistent with the difference in the fraction of deep convection between El Niño and La Niña periods (Fig. 3c).

The impacts of ENSO on the fraction of deep and large systems over the Maritime Continent region are unique, and provide evidence that the phase of ENSO indeed plays an important role in influencing the properties of precipitation systems over this region, which is consistent with some earlier studies (Wang and Rui 1990; Hamid et al. 2001; Xie et al. 2009). Figure 5a shows that the EMC observes a positive correlation between the MEI and the fraction of deep convection. In contrast, the WMC observes negative correlation between the MEI and the fraction of deep convection. Figure $5 \mathrm{~b}$ shows that the entire Maritime Continent has more uniform negative correlation between the MEI and the fraction of MCSs. This is consistent with the ENSO precipitation anomaly in the region, providing evidence 


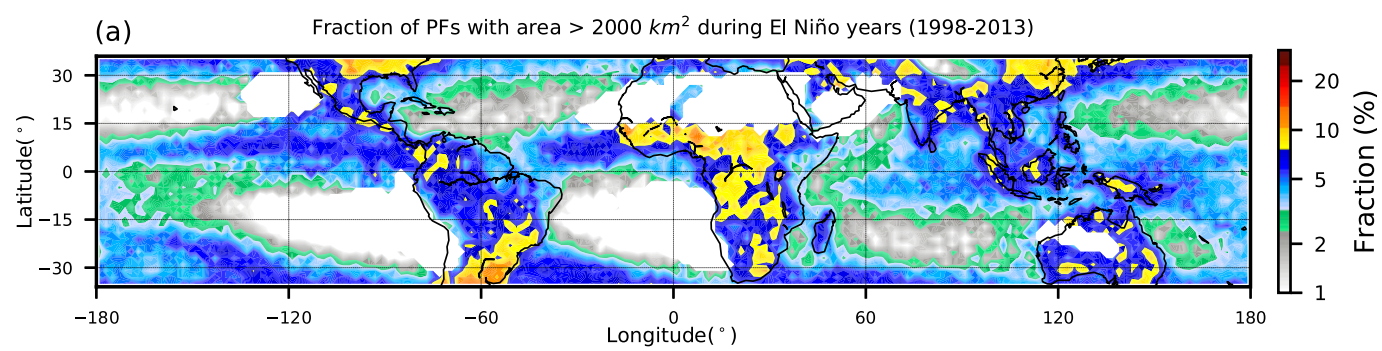

(b) Fraction of PFs with area $>2000 \mathrm{~km}^{2}$ during La Niña years (1998-2013)

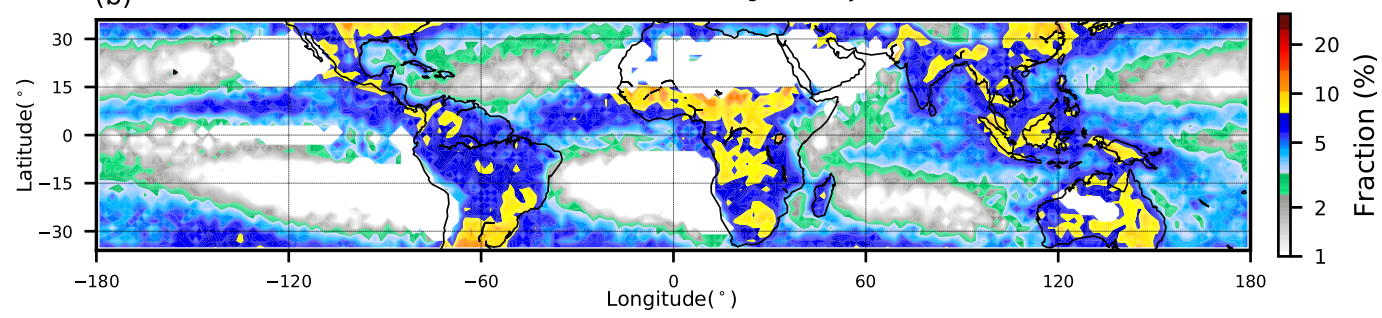

(c)

Difference of fraction (EI Niño - La Niña)

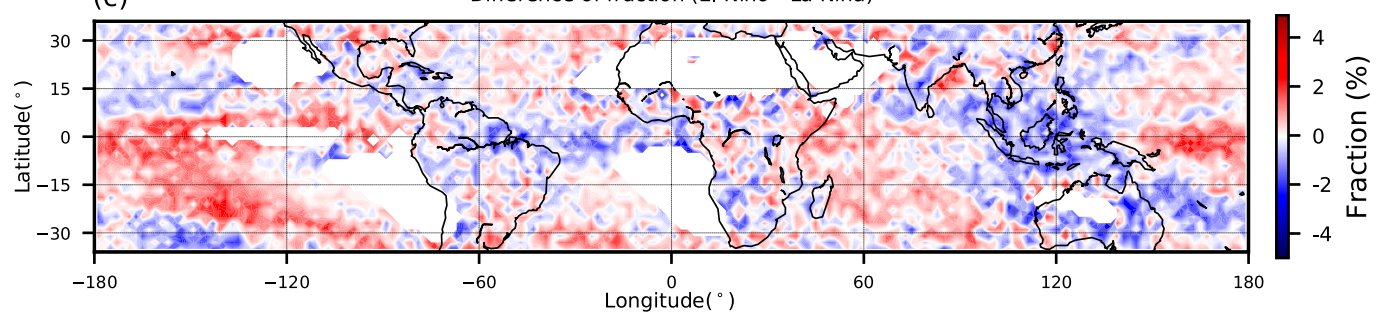

FIG. 4. As in Fig. 3, but for PFs with area $>2000 \mathrm{~km}^{2}$.

that in the region, MCSs play an important role in the anomalous precipitation during different phases of ENSO events.

Since there are distinct differences in the fraction of deep and large convection between the two phases of ENSO, especially over some particular regions, six regions (enclosed by the black box in Fig. 5b), including CPACI $\left(8^{\circ} \mathrm{S}-5^{\circ} \mathrm{N}, 150^{\circ} \mathrm{W}-180^{\circ}\right)$, WMC, EMC, the Gulf of Mexico (GM: $\left.21^{\circ}-30^{\circ} \mathrm{N}, 85^{\circ}-95^{\circ} \mathrm{W}\right)$, ARGEN $\left(28^{\circ}-\right.$ $\left.35^{\circ} \mathrm{S}, 53^{\circ}-65^{\circ} \mathrm{W}\right)$, and AUS $\left(15^{\circ}-20^{\circ} \mathrm{S}, 140^{\circ}-160^{\circ} \mathrm{E}\right)$, are chosen to investigate the seasonal effect of ENSO on the characteristics of precipitation systems in this study. Then, the mean volumetric rainfall occurrence and contribution of rainfall to the total rainfall over these regions are examined further.

\section{d. Seasonal variability in the correlation between ENSO and different systems}

It is well known that the properties of precipitation systems vary seasonally (Romatschke et al. 2010). Thus, the seasonal variations of the coefficient determination $R^{2}$ between the MEI and the fraction of deep convection and MCSs are summarized in Fig. 6. Symbols with a larger size indicate a significant correlation between the MEI and the fraction of either the height or horizontal size of the precipitation systems, with a $p$ value less than 0.05 .

The CPACI has a relatively higher coefficient of determination seasonal variability of correlations between MEI and the fraction of deep and large precipitation systems than other regions throughout the year. The CPACI, with the exception of April, shows a significant correlation between the MEI and the fraction of tall storms (Fig. 6a) in almost all months, with the exception of March, April, and June. This indicates that the presence of El Niño conditions is correlated to the fraction of deep storms throughout the entire year. The CPACI also observes a significant correlation between the MEI and the fraction of horizontal storm size in all seasons except the Northern Hemispheric (NH) summer months of June, July, August (JJA), and September. In all other months, the results show that the fraction of MCSs over the region are associated with ENSO events.

The Maritime Continent region shows uniquely different characteristics of precipitation systems on the eastern and western portions, during the two phases of ENSO. This is also observed in the seasonality of this region. First, more months are found to be correlated with the fractions of deep convection and MCSs over the 

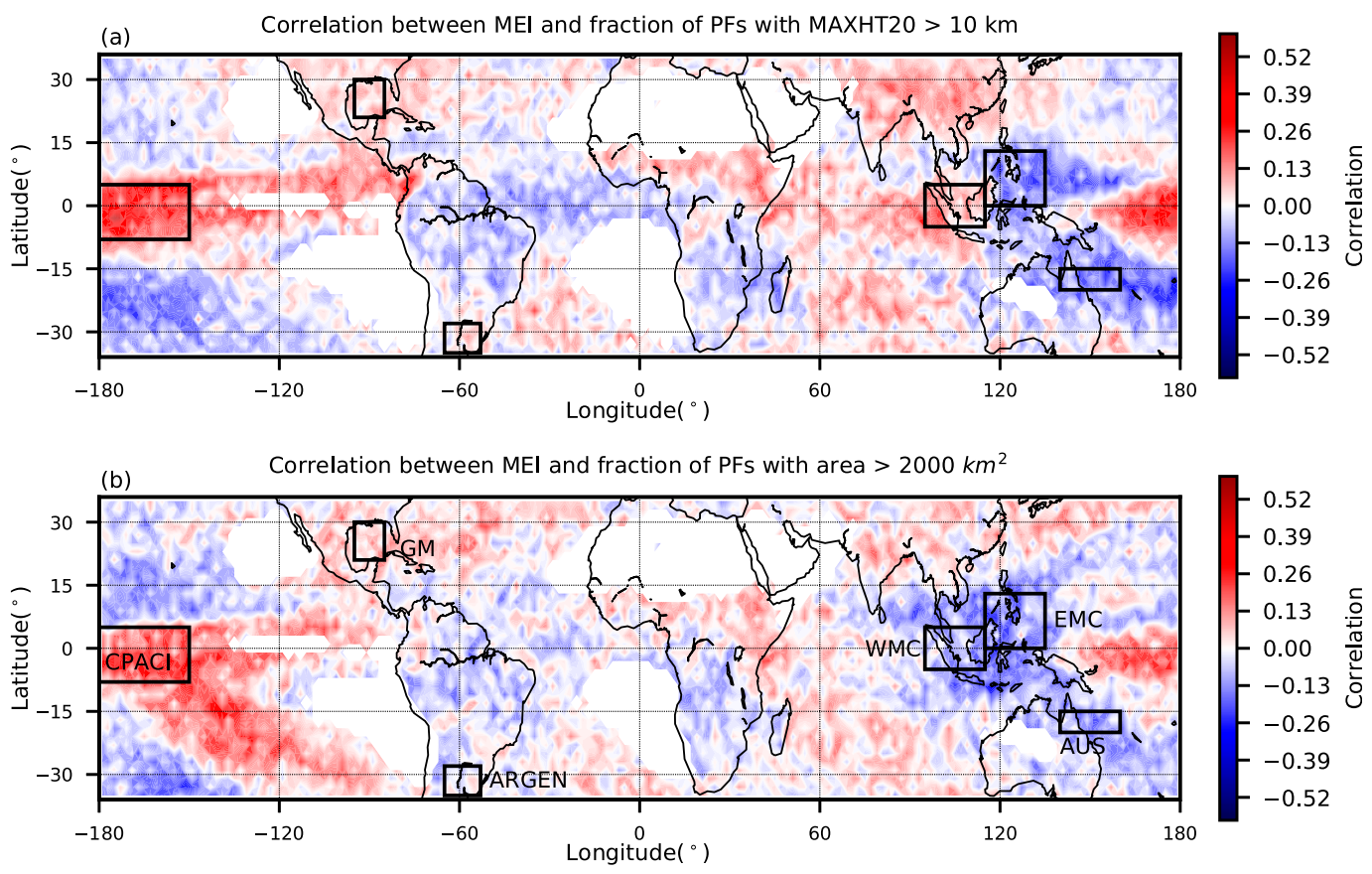

FIG. 5. Monthly correlation (a) between the MEI and the fraction of PFs with MAXHT2 $>10 \mathrm{~km}$ on a $2^{\circ} \times 2^{\circ}$ grid and (b) between the MEI and the fraction of PFs with area $>2000 \mathrm{~km}^{2}$. Boxes with samples $<1000$ are blank.

EMC than that over the WMC (red and green symbols in Fig. 6). This indicates that ENSO events have larger influences on the properties of convection over the eastern portion of the Maritime Continent, compared to the western portion. Second, the correlation between the MEI and the fraction of deep convection in the WMC is significant in September and October, coincident with the peak phase of the Indian Ocean dipole
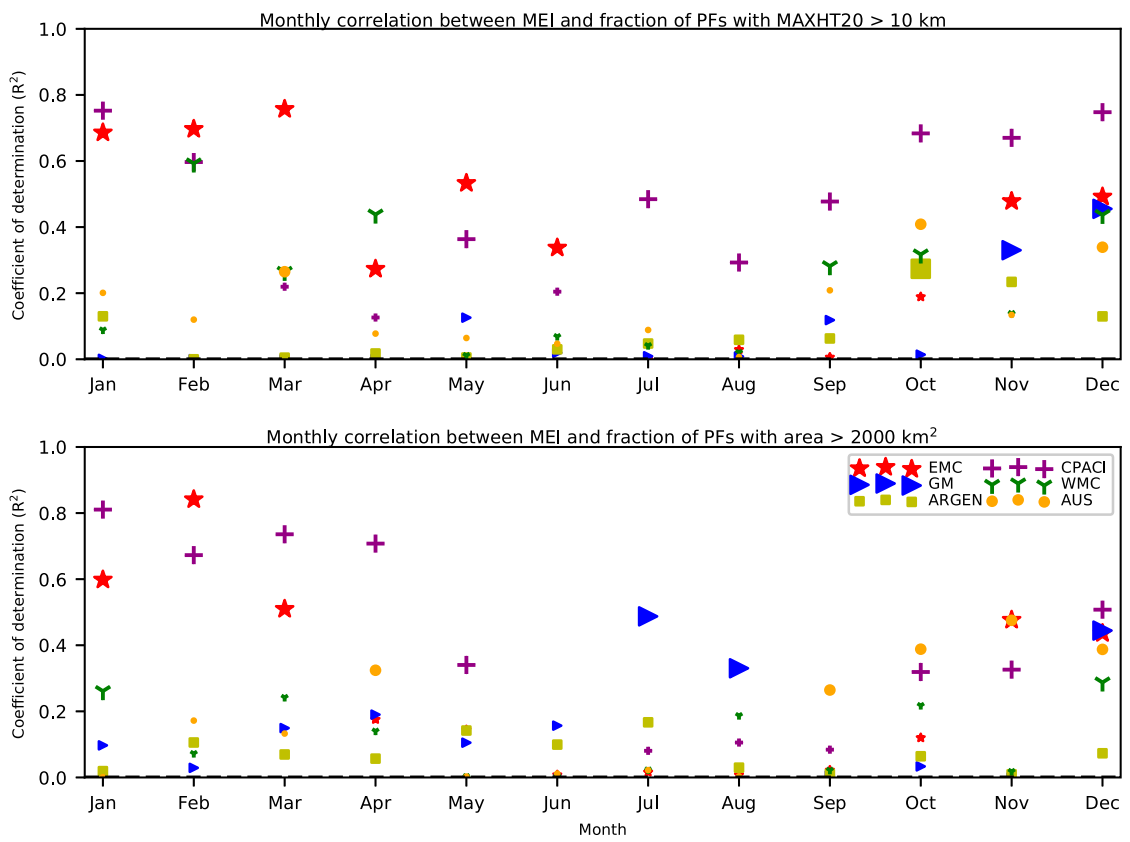

FIG. 6. Monthly correlation between the MEI and the fraction of deep convection and MCSs over selected regions. Fraction of deep convection and MCSs are significantly correlated with the MEI with $p$ value $<0.05$. The significant correlation coefficients are larger than nonsignificant ones. 

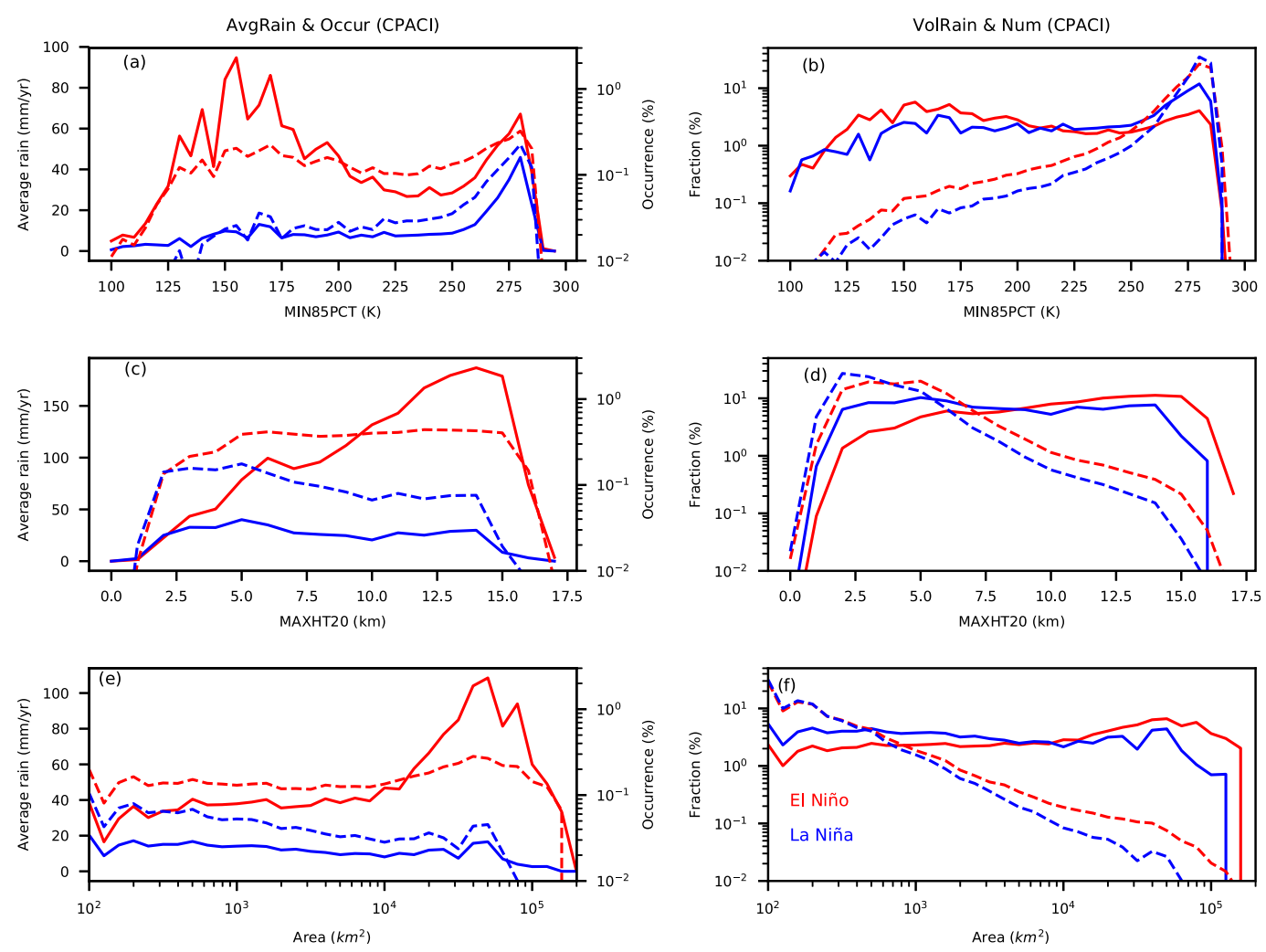

FIG. 7. Comparison of various rainfall-related parameters as a function of (top) MIN85PCT, (middle) MAXHT20, and (bottom) the size of PFs over different phases of ENSO over CPACI. (a) Annual mean rainfall (solid) and occurrence (dashed) as a function of MIN85PCT. (b) The number (dashed) and volumetric rainfall contribution (solid) to the total PFs as a function of MIN85PCT. (c) As in (a), but as a function of MAXHT20. (d) As in (b), but as a function of MAXHT20. (e) As in (a), but as a function of convective size. (f) As in (b), but as a function of convective size.

(IOD), often September and October (Saji et al. 1999), while it is not true in the EMC in September and October. Independent of ENSO in the Pacific Ocean, the IOD is an oscillatory mode of coupled oceanatmosphere variability in the Indian Ocean (Webster et al. 1999).

Over AUS, the fraction of deep convection is found significantly correlated $\left(R^{2}>0.35\right)$ with the MEI in October and December. In addition to April and December, significant correlations $(p<0.05)$ between the MEI and the fraction of MCSs are also found during boreal fall (September-November), which is consistent with previous studies (McBride and Nicholls 1983; Ropelewski and Halpert 1987). The fraction of MCSs is significantly correlated $\left(R^{2}>0.4\right)$ to the MEI in the GM in July and December, while the coefficient of determination between the fraction of deep storms and the MEI is greater than 0.35 in November and December. The only extended period of time that the fraction of deep storms in ARGEN noticeably correlated $\left(R^{2}>\right.$ $0.35)$ to the MEI is in October. Overall, the directly linked regions (CPACI, EMC and WMC) showed much higher correlation between the MEI and the fraction of deep and large systems than the indirectly linked regions.

\section{e. Precipitation contribution inside the Pacific Walker circulation}

To compare the properties of PFs during two ENSO phases, the histogram of PFs as a function of different parameters is created using the 3-yr compiled dataset. Figure 7 shows the histograms of $\mathrm{PFs}$ and their rainfall contributions as a function of the MIN85PCT, MAXHT20, and area during the two phases of ENSO over the CPACI region. In general, there are more precipitation events (dashed lines in Figs. 7a, 7c, and 7e) that occurred over the CPACI, during El Niño than during La Niña periods. Another evident feature is the peak located at the heavy end of the mean rainfall distribution during El Niño periods. Precipitation systems that are deep $(>12 \mathrm{~km})$, large $\left(>10000 \mathrm{~km}^{2}\right)$, and intense (MIN85PCT $<200 \mathrm{~K})$ have much larger $(\sim 110.4$, 

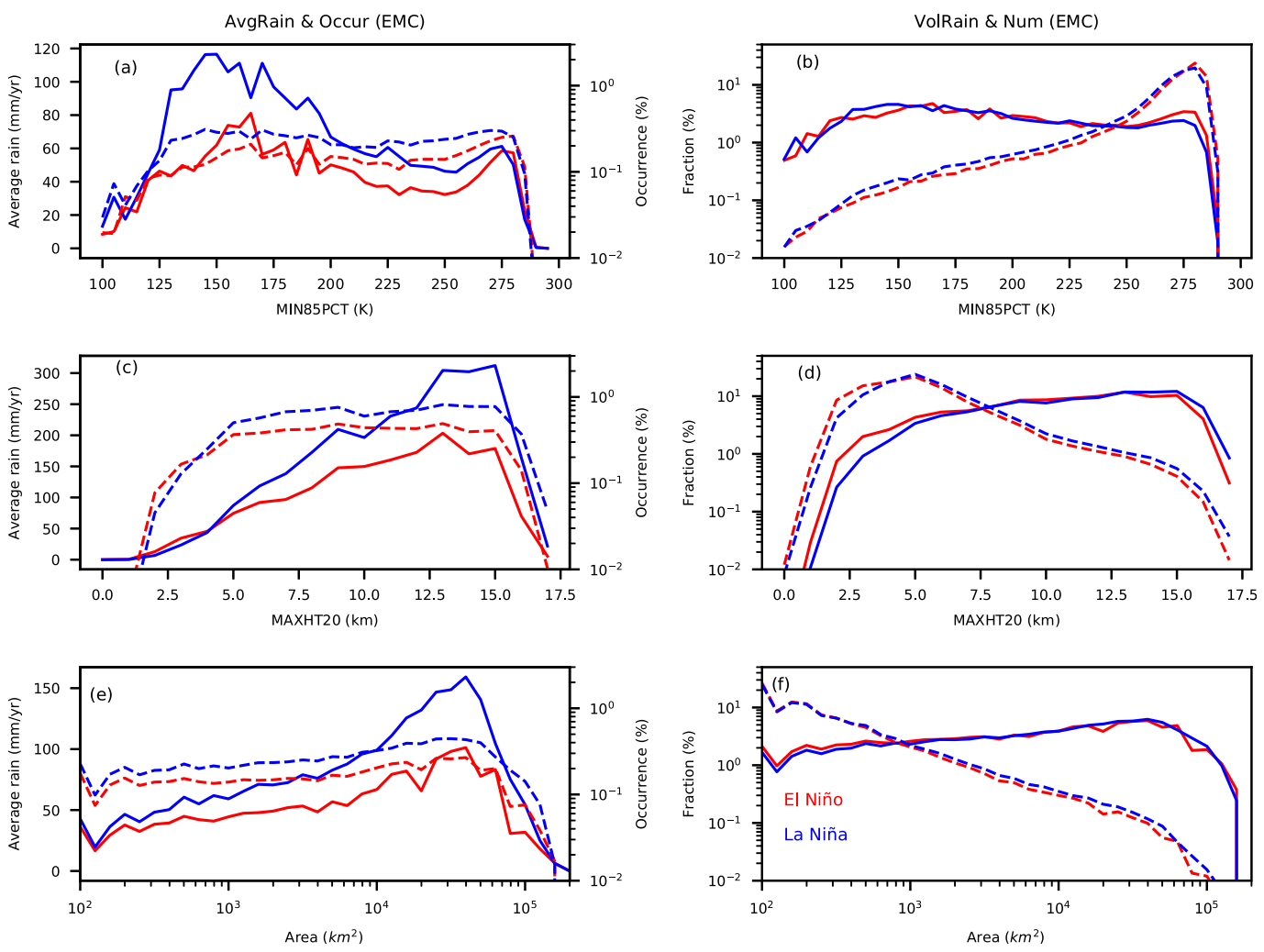

FIG. 8. As in Fig. 7, but for EMC.

27.6, and $42.3 \mathrm{~mm} \mathrm{yr}^{-1}$ more) mean annual rainfall during the warm phase of ENSO over the CPACI when compared to that during the cold phase. The difference between the two phases of ENSO in the population and rainfall fraction of PFs as a function of intensity is shown in Figs. 7b, 7d, and 7f. The largest portion of precipitation events is contributed from warm features, with the minimum $85-\mathrm{GHz}$ PCT greater than $270 \mathrm{~K}$ during both periods. In terms of the percentage of both the number and volumetric rainfall, the distribution is shifted to more intense PFs with colder $85-\mathrm{GHz}$ PCT during El Niño than La Niña distribution. When examining the distribution as a function of MAXHT20 and area, the number and rainfall fraction shift to the deeper, larger, and more intense end of the distribution during the warm phase of ENSO relative to the distribution during the cold phase of ENSO in the CPACI. In other words, precipitation systems tend to be deeper, larger, and more intense during El Niño periods in the CPACI. A small portion of PFs with MAXHT20 greater than $10 \mathrm{~km}(2.7 \%)$ and area greater $5000 \mathrm{~km}^{2}(1.1 \%)$ produces a significant total rainfall $(\sim 52 \%$ and $51 \%)$ (figure not shown). While shallow $(<6 \mathrm{~km})$ and small systems $\left(<1000 \mathrm{~km}^{2}\right)$ contribute only about $19 \%$ and $29 \%$ to the total rainfall with a much higher percentage of total PFs (78\% and $94 \%)$. Therefore, a slight shift on the heavy end of the distribution of precipitation systems could lead to a large difference in the total rainfall.

The opposite is true for the anomalous precipitation over the EMC as shown in Fig. 8. Specifically, there are more precipitation events and a larger mean annual rainfall, as well as higher occurrence of intense precipitation systems (MIN85PCT $<200 \mathrm{~K})$, during La Niña than during El Niño periods. Figure $8 d$ shows a slight shift toward deeper systems taking place in the EMC during La Niña periods. Meanwhile, more largearea precipitation systems $\left(>10000 \mathrm{~km}^{2}\right)$ are found over the EMC. The increase of intense, deep, and largearea precipitation systems over the EMC during $\mathrm{La}$ Niña periods is consistent with the enhanced Walker circulation (Lindzen and Nigam 1987). More precipitation events and a larger mean annual rainfall, as well as more large-area precipitation systems $\left(>10000 \mathrm{~km}^{2}\right)$, are also found over the WMC during La Niña intervals (Fig. 9). However, a slight shift toward deeper systems during El Niño periods is found over the EMC. This indicates a higher faction of deep convection during the warm phase of ENSO occurring over this region (Fig. 9d). 

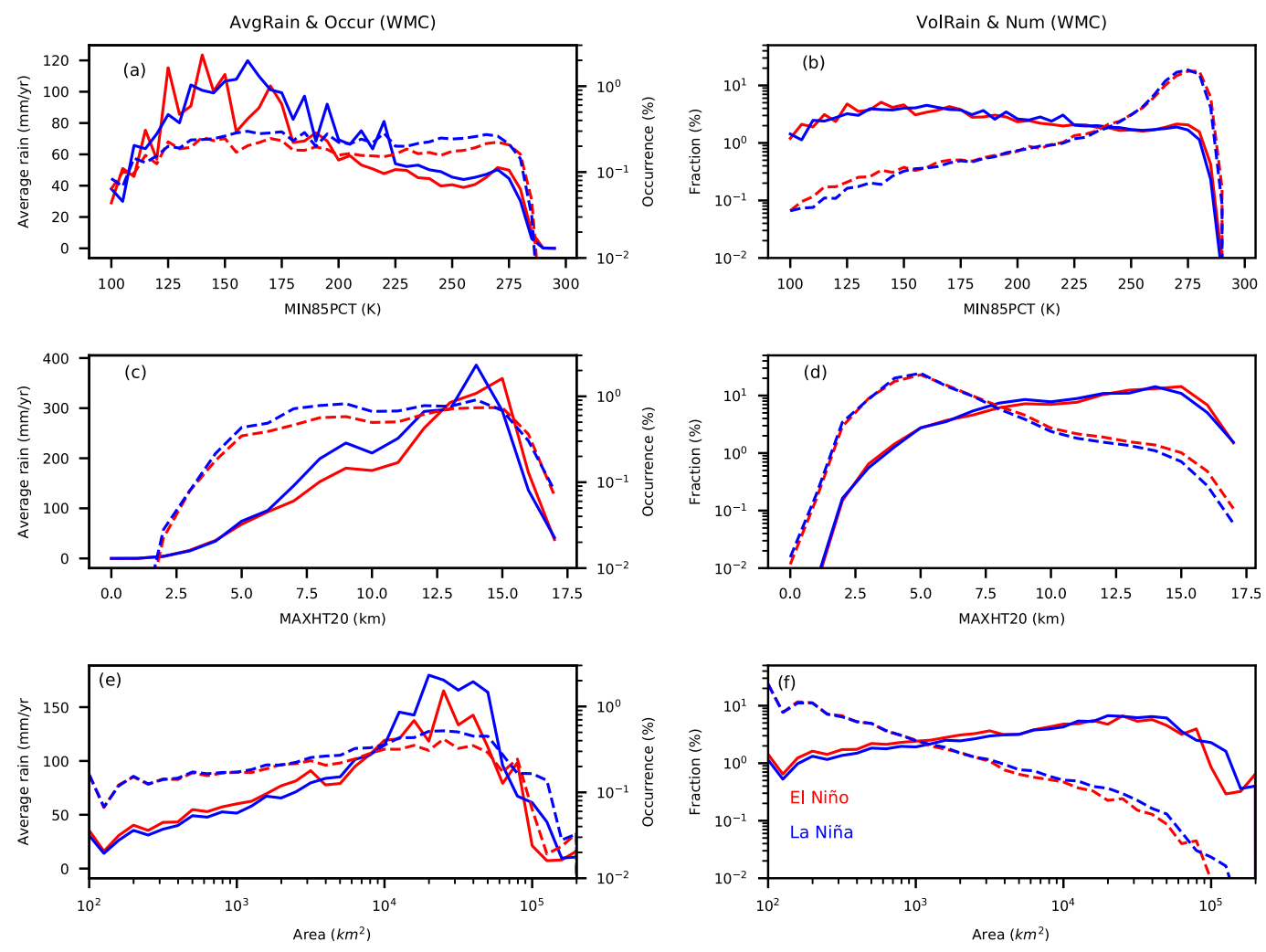

FIG. 9. As in Fig. 7, but for WMC.

These results suggest that the warm and cold phases of ENSO can indeed influence the types of precipitation events (i.e., deep convection, or MCSs) at a regional scale. Specifically, in the Maritime Continent, the eastern portion receives an increase in the fraction of intense/deeper systems and MCSs during La Niña periods. In spite of the increase in the fraction of MCSs, the western portion does not have the same increase in the occurrence of deep systems during La Niña periods, which is consistent with past work that showed that Indonesia observed an increase in lightning activity, accompanied by a decrease in precipitation during the strong El Niño event of 1997/98 (e.g., Hamid et al. 2001). Higher annual rainfall and occurrence of MCSs are found both over the eastern and western portions of the Maritime Continent. However, the difference between the two phases of ENSO is smaller over the WMC than that over the EMC (Figs. 8e, 9e). According to Meyers et al. (2007), a positive temperature anomaly was found in the western portion of the Maritime Continent, during the negative IOD year [with warm sea surface temperature (SST) anomaly in the eastern Indian Ocean] with no ENSO event occurring. This provides supportive evidence that the variation of precipitation in the Maritime Continent is not only affected by ENSO but also influenced by the IOD, consistent with previous studies (e.g., Saji et al. 1999; Webster et al. 1999; Ashok et al. 2003).

\section{f. Precipitation contribution outside the Pacific Walker circulation}

The precipitation systems described above over the areas that are directly related to ENSO provide insight into the properties of the anomalous precipitation observed in those regions in response to ENSO. Similar figures are created for another three regions, with an indirect link to ENSO, including the GM, ARGEN, and AUS. Figure 10 shows distinct differences exists among the two phases of ENSO over the GM. Larger occurrence of PFs and mean annual rainfall are found during El Niño years, especially for the intense (MIN85PCT $<$ $150 \mathrm{~K})$, deep $(>10 \mathrm{~km})$, and large systems $\left(>10000 \mathrm{~km}^{2}\right)$. This indicates that El Niño also can shift the number and volumetric rainfall distribution toward deeper, larger, and more intense events over the GM, similar to that over the CPACI region.

As one of the favorite regions of deep convection (Liu et a. 2007; Romatschke and Houze 2010; Liu and Liu 2018) and MCSs (e.g., Mohr and Zipser 1996; Nesbitt et al. 2006; Salio et al. 2007) on Earth, ARGEN is worth 

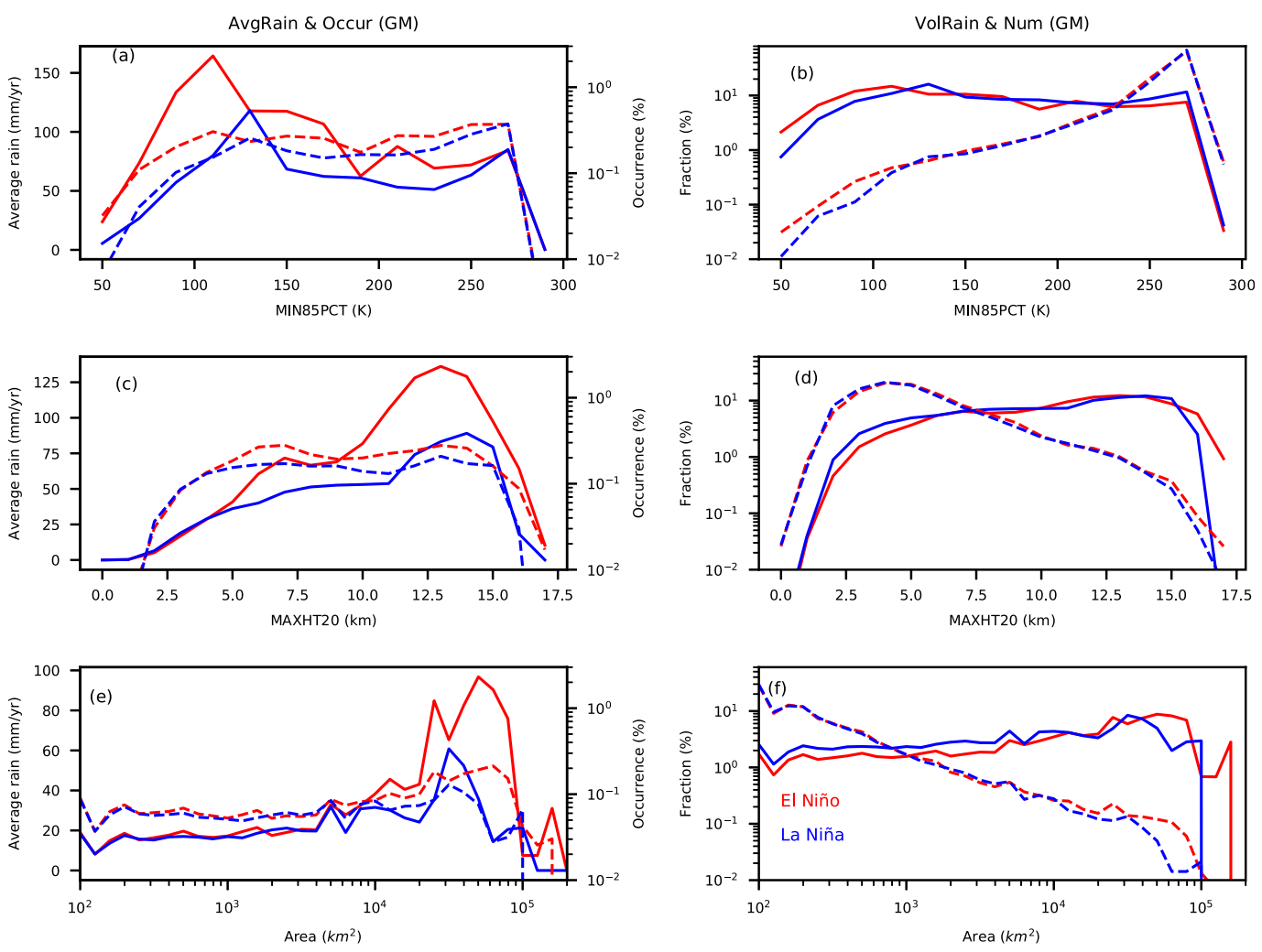

FIG. 10. As in Fig. 7, but for GM.

our particular attention on the different effects of the different phases of ENSO on the properties of precipitation systems. First, there is a higher frequency and larger mean rainfall of intense, deep, and large precipitation systems found over ARGEN during the warm phase of ENSO than that during the cold phase of ENSO (Figs. 11a,c,e). Second, the shift to the heavy end of the distribution of PFs as a function of MIN85PCT, MAXHT20, and area is more prominent over ARGEN during El Niño conditions than that during La Niña conditions, compared to the three regions mentioned above. It implies that ENSO cycles do have an effect on the properties of precipitation systems over ARGEN.

Precipitation anomalies in Australian has been associated with the strong influence of ENSO (e.g., Ropelewski and Halpert 1987; Power et al. 1998; Kiem and Franks 2004). Risbey et al. (2009) suggest that rainfall in the east of Australia has the strongest relationship with ENSO, where El Niño (La Niña) events are associated with decreased (increased) rainfall. Therefore, a similar analysis with other regions is applied to the AUS to further explore the variations in the properties of the precipitation systems (Fig. 12). Higher number fraction of intense convection (MIN85PCT $<200 \mathrm{~K}$ ) is found during La Niña conditions than that during El Niño conditions (Fig. 12b). Higher mean rainfall is consistent with the increasing precipitation during La Niña conditions over the AUS (Figs. 12c,e). The difference in the occurrence between the two phases of ENSO indicates that the precipitation anomaly is associated with variation in the population of precipitation events. Higher volumetric rain contribution from shallow $(<6 \mathrm{~km})$ and small $\left(<1000 \mathrm{~km}^{2}\right)$ precipitation systems is found during El Niño periods, while higher population fraction of deep $(>10 \mathrm{~km})$ and large-size $\left(>1000 \mathrm{~km}^{2}\right)$ precipitation systems is found during La Niña periods (Figs. 12d,f). In other words, a decrease of ENSO-related rainfall over the AUS is a result of fewer precipitation events and a higher fraction of shallow and small precipitation systems occurring during El Niño periods.

\section{g. Properties of precipitation systems under two ENSO phases over specific regions}

In summary, the regional average rain and occurrence, fraction of PFs, and volumetric rainfall contribution of deep convection and MCSs during each phase of ENSO are listed in Table 1. Almost 4 times the average rainfall is observed over the CPACI in the warm phase versus the cold phase of ENSO. This is consistent with the results shown in Fig. 1c. Even with a low 

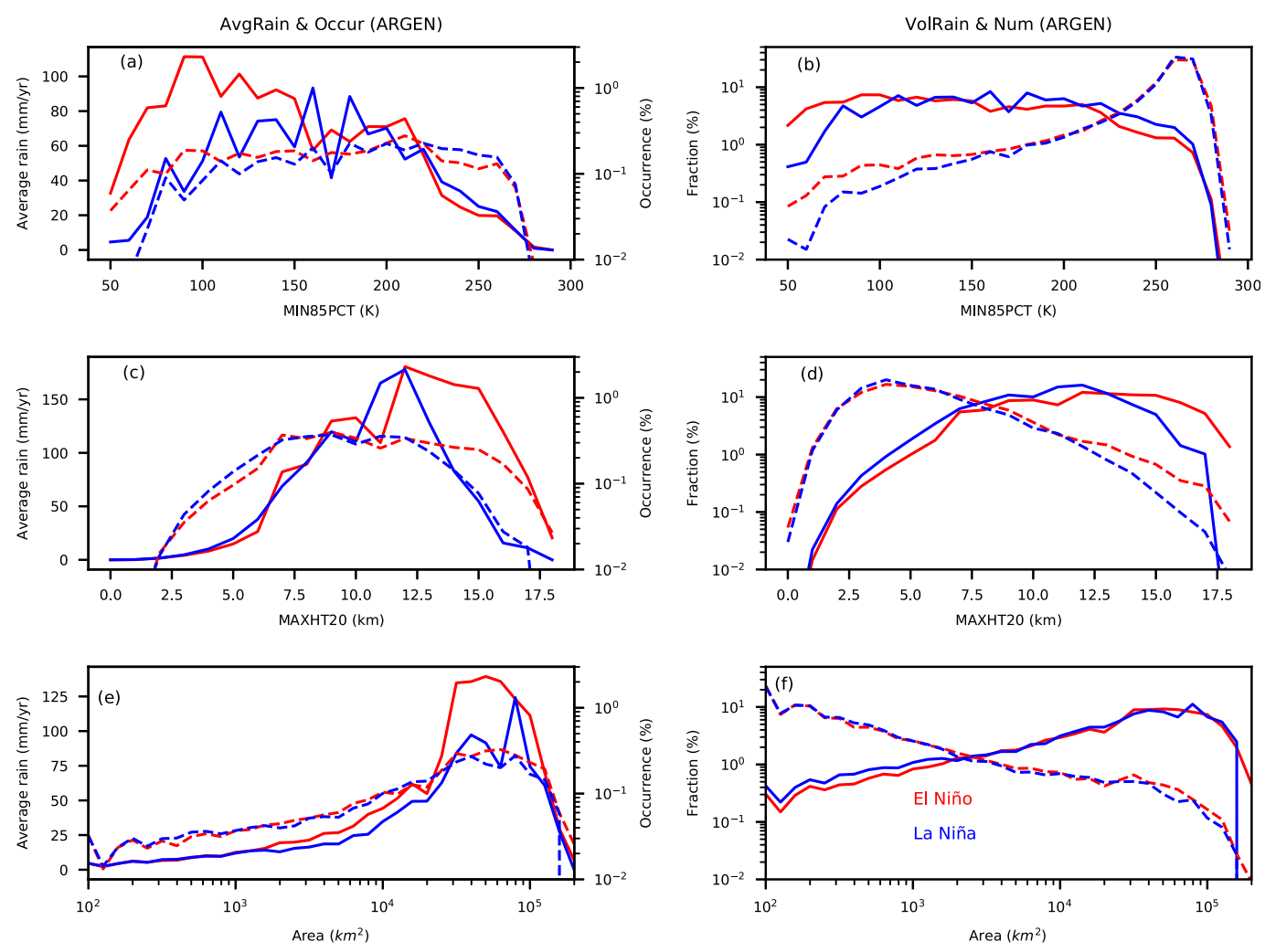

FIG. 11. As in Fig. 7, but for ARGEN.

occurrence $(<6 \%)$ and small fraction of deep convection and MCSs $(<10 \%)$, these deep and large precipitation systems can contribute more than $60 \%$ to the total rainfall, which is consistent with previous studies (e.g., Nesbitt et al. 2006). The EMC and AUS display a lower occurrence, fraction, and volumetric rainfall contribution of deep convection and MCSs during the warm phase of ENSO, while the reverse is true over other selected regions, including the CPACI and ARGEN. With a lower occurrence during El Niño periods than that of during La Niña periods, deep convection over the WMC exhibit a higher fraction and contribute more to the total rainfall. It is important to note that in the WMC, deep convection exhibits a larger occurrence in La Niña periods but a higher fraction in El Niño periods. This indicates that although there is a shift toward a taller distribution during El Niño, this does not necessarily indicate that a larger occurrence of deep systems will be observed. The higher observed occurrence and fraction of MCSs, as well as higher fraction of deep convection, can cause more average rainfall in the warm phase of ENSO than that in the cold phase. The difference of occurrence, fraction, and volumetric rainfall contribution of deep and large precipitation systems during different phases of ENSO provide supportive evidence that ENSO-related anomalous precipitation is not only related to the number of events, but also associated with the depth, intensity, and area of events.

It is typical that the precipitation systems are dominated by shallow (MAXHT20 $<6 \mathrm{~km}$ ) and small $\left(<1000 \mathrm{~km}^{2}\right)$ systems (figure not shown). However, the small fraction of the deep and large systems account for a large proportion of the total rainfall (Table 1). To highlight the role of deep and large precipitation systems, we create the median profile of 20- and 40-dBZ area in PFs over each region, using only the PFs with large volumetric rainfall [e.g., CPACI PFs > $63110 \mathrm{~km}^{2} \mathrm{~mm} \mathrm{~h}^{-1}$ during El Niño periods (Fig. 13a)] that account for the $50 \%$ of the total volumetric rainfall. In the CPACI (Fig. 13a), higher MAXHT20, larger size of the 40- and 20-dBZ areas are found during El Niño periods, which indicates a shift toward deeper, more intense, and larger PFs during the warm phase of ENSO relative to the cold-phase distribution. Opposite patterns are observed in storm size for both the EMC and WMC (Figs. 13b,c), with larger size of $20 \mathrm{dBZ}$ at low levels $(<6 \mathrm{~km})$ being observed during La Niña. Together with the larger population fraction of MCSs during La Niña periods (Fig. 4), the larger size of MCSs in both the EMC and WMC indicates that the size of the 

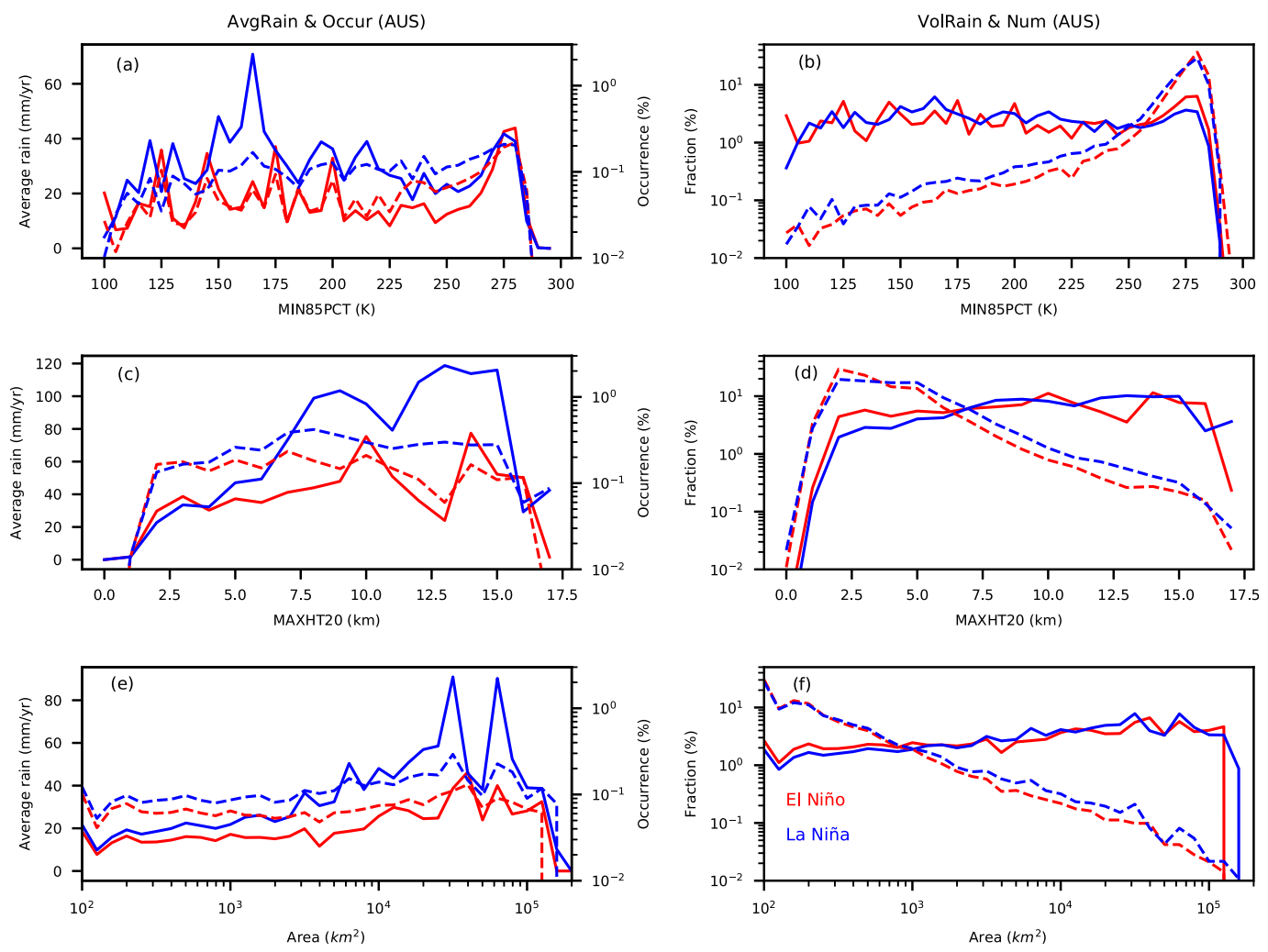

FIG. 12. As in Fig. 7, but for AUS.

precipitation systems may also play an important role in the anomalous rainfall throughout the regions (Figs. 13b,c). Even with relative small correlation values (Figs. 5, 6), the difference in characteristics of PFs over GM and ARGEN is significant among the different phases of ENSO. The profiles of 20- and 40-dBZ area (Figs. 13d,e) during El Niño and La Niña periods suggest that ENSO has a significant influence on the intensity, heights, and size of convection systems over the GM and ARGEN. A larger size of $20 \mathrm{dBZ}$ at low levels is observed over the AUS is consistent with the higher population fraction of large-size precipitation systems during La Niña periods (Fig. 13f).

\section{Summary}

Based on 16 years of TRMM observations, distinct differences in the annual mean rainfall between different phases of ENSO are consistent with the welldocumented anomalous precipitation over various regions (e.g., Ropelewski and Halpert 1987; Dai and Wigley 2000; Yang and DelSole 2012). This study examines the variations of properties of precipitation systems over different regions that result in the anomalous precipitation under warm and cold ENSO phases. First, two types of precipitation systems are focused. Deep convection is defined as precipitation systems

TABLE 1. Average rain amount, occurrence, fraction, and volumetric rain contribution of deep convection and MCSs during El Niño and La Niña (in parentheses) over different regions.

\begin{tabular}{|c|c|c|c|c|c|c|c|}
\hline & \multirow{2}{*}{$\begin{array}{c}\text { Rain } \\
\left(\mathrm{mm} \mathrm{yr}^{-1}\right)\end{array}$} & \multicolumn{3}{|c|}{ Deep convection (20-dB $Z$ echo top $>10 \mathrm{~km})$} & \multicolumn{3}{|c|}{ MCSs $\left(\right.$ area $\left.>2000 \mathrm{~km}^{2}\right)$} \\
\hline & & Occurrence $(\%)$ & Fraction (\%) & Contribution $(\%)$ & Occurrence $(\%)$ & Fraction $(\%)$ & Contribution (\%) \\
\hline CPACI & $1663(389)$ & $2.6(0.4)$ & $3.5(1.9)$ & $62.8(35.4)$ & $3.3(0.6)$ & $3.6(2.4)$ & $71.2(46.7)$ \\
\hline EMC & $1730(2576)$ & $2.6(4.6)$ & $5.8(7.1)$ & $61.9(67.1)$ & $3.3(5.7)$ & $4.5(5.3)$ & $68.7(73.2)$ \\
\hline WMC & $2463(2615)$ & $4.0(4.5)$ & $10.6(9.4)$ & $71.4(68.2)$ & $4.8(6.0)$ & $6.9(7.8)$ & $75.2(78.9)$ \\
\hline GM & $1114(734)$ & $1.4(1.0)$ & $7.2(7.6)$ & $65.0(59.6)$ & $2.0(1.3)$ & $4.9(4.7)$ & $78.9(70.2)$ \\
\hline ARGEN & $1113(911)$ & $2.0(1.4)$ & $10.3(8.7)$ & $74.6(65.4)$ & $3.1(2.6)$ & $9.6(9.2)$ & $92.7(90.2)$ \\
\hline AUS & 712 (1172) & $1.0(1.8)$ & $2.6(3.9)$ & $54.1(58.8)$ & $1.5(2.8)$ & $3.5(4.6)$ & $71.1(76.5)$ \\
\hline
\end{tabular}



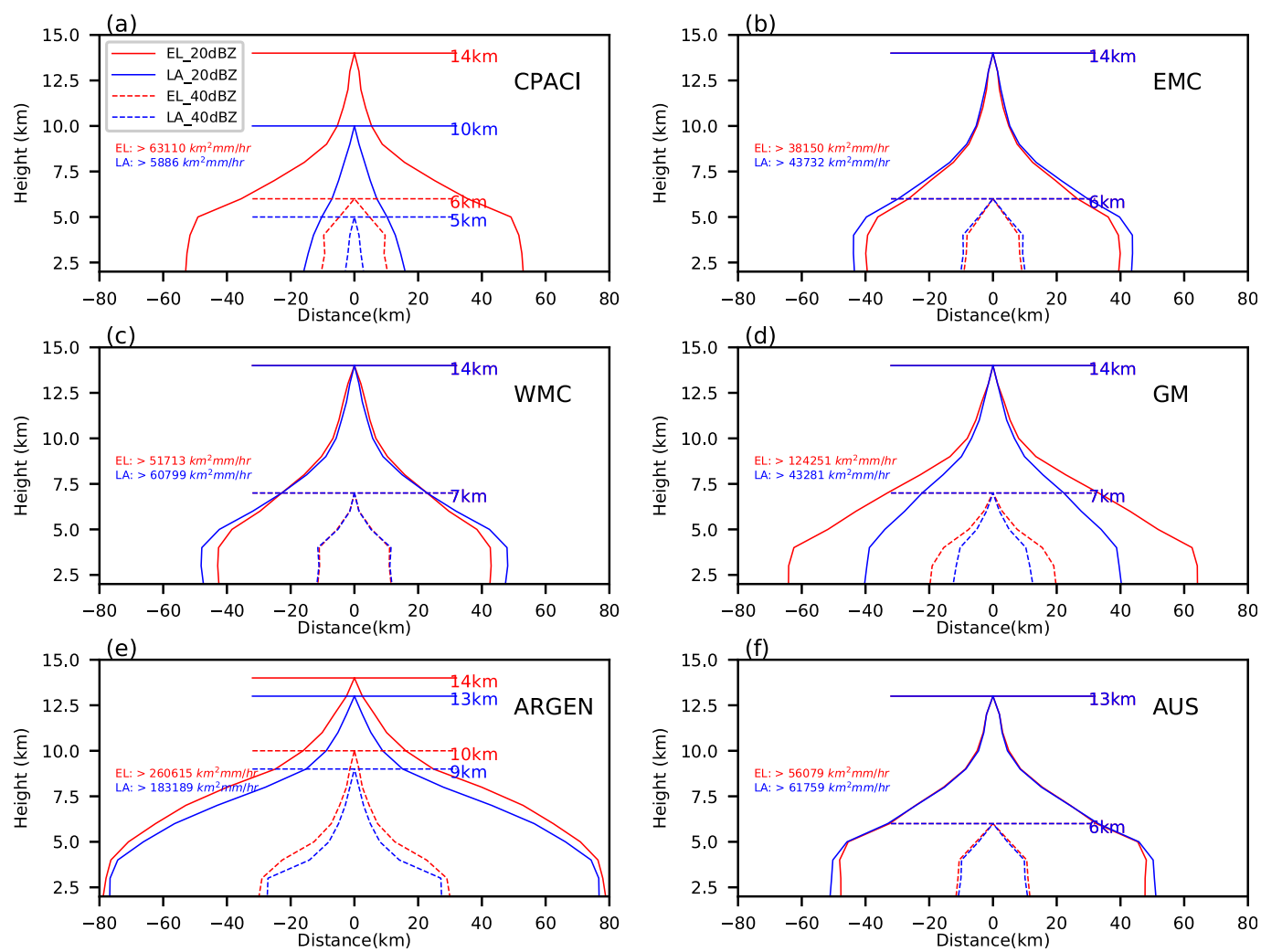

FIG. 13. Median length scale of PFs during El Niño (red) and La Niña (blue) periods over selected regions. PFs from the top $50 \%$ volumetric rainfall contribution to the total rainfall based on a 3-yr compiled dataset are used here. Regions are (a) CPACI, (b) EMC, (c) WMC, (d) GM, (e) ARGEN, and (f) AUS. The length scale is defined as $L= \pm(A / \pi)^{0.5}$, where $A$ is the area of 20 or $40 \mathrm{dBZ}$ at different altitudes within each PF. It represents the radius of PFs at each altitude, assuming the symmetric conical shape of a region with 20 or $40 \mathrm{dBZ}$. Solid lines mark the average maximum heights of $20 \mathrm{dBZ}$, and dashed lines mark the average maximum heights of $40 \mathrm{~dB} Z$.

with a $20-\mathrm{dB} Z$ echo top greater than $10 \mathrm{~km}$ while MCSs are defined with precipitation systems having an area larger than $2000 \mathrm{~km}^{2}$. The fraction of these two types of precipitation systems during different phases of ENSO, as well as their correlations with the MEI, are examined over regions across the tropics and subtropics. The results reveal that pronounced effects from ENSO on the deep convection and MCSs are found over specific regions, including the central Pacific (CPACI), the western Maritime Continent (WMC), the eastern Maritime Continent (EMC), Gulf of Mexico (GM), Argentina (ARGEN), and Australia (AUS).

The seasonal variations of influences from ENSO are further explored. The coefficient of determination is more pronounced in the $\mathrm{NH}$ winter half-year in comparison to the summer half-year over CPACI, the Maritime Continent, and AUS. The fraction of deep convection is found strongly correlated $\left(R^{2}>0.6\right)$ to the MEI in October-December and January over CPACI, while it is true in January-March over EMC. The effect of ENSO on deep convection and MCSs over GM and
ARGEN is less pronounced in coefficient of determination $\left(R^{2}<0.2\right)$, compared to other selected regions.

The shift of the spectra of PFs in both number and rainfall contribution during different phases of ENSO, as a function of MIN85PCT, MAXHT20, and area, suggests that precipitation anomaly over these regions are related to the number of precipitation events, as well as the fraction of deep, intense, and large precipitation systems. In other words, ENSO not only could affect the number of precipitation events but also could shift the spectrum of precipitation systems of various properties. Therefore, an increase of rainfall during El Niño periods over CPACI, GM, and ARGEN is a result of more precipitation events and a higher fraction of intense, deep, and large precipitation systems. The opposite is true for AUS. The Maritime Continent is a unique region because of the effect of both the IOD and ENSO. A higher contribution from small-size precipitation systems $\left(<1000 \mathrm{~km}^{2}\right)$ is found in both the eastern and western portions of the Maritime Continent during El Niño conditions than that during La Niña conditions. 
However, in terms of both the number and volumetric rainfall contribution, a higher fraction of deep convection $(>12 \mathrm{~km})$ over WMC is found during El Niño conditions, while a higher fraction of deep convection over EMC is found during La Niña conditions.

Though ENSO episodes vary with institution and methods employed to define an episode, the 3 years of data used to investigate the effectiveness of ENSO over selected regions, constituted by the three strongest ENSO months for each month during 1998-2013, lead to similar categorization as that based on other ENSO indices, such as Niño-3.4. Nevertheless, this study suggests the importance of ENSO variability on the relatively small number of intense, deep, and large precipitation systems (approximately $1.5 \%-9 \%$ ) in certain regions of the globe. Although these systems are small in number, they contribute the majority of rainfall in these regions. When excluding the vast majority of PFs that are small and shallow, clear regional shifts toward deeper, larger, and more intense systems can be observed during different phases of ENSO. The shifts are associated with changes in the strength and location of the Walker circulation, as a result of changes in the wind stress and sea surface temperature (e.g., Rasmusson and Carpenter 1982; Lindzen and Nigam 1987; Trenberth et al. 1998). In addition, a stronger westerly at $200-\mathrm{hPa}$ level is found during the warm phase of ENSO over GM (Arkin 1982), coincidence with a tendency for more frequent storms and precipitation over this region (Ropelewski and Halpert 1986). Hill et al. (2011) found the highest rainfall occurred during El Niño periods in South America due to the strengthening of the South American low-level jet, based on an atmospheric general circulation model. Therefore, ENSO plays a vital role in the precipitation anomaly by modulating the size and intensity of precipitation systems. The difference in rain occurrence, volumetric rainfall contribution from PFs of various intensity, depth, and size during the warm and cold phases of ENSO may help provide a better insight into precipitation anomalies in the future.

Acknowledgments. The authors thank three anonymous reviewers for their valuable comments and suggestions to help improve this manuscript significantly. This research was supported by NASA Precipitation Measurement Mission Grants NNX16AD76G under the direction of Dr. Ramesh Kakar and NNX16AH74G under the direction of Dr. Erich Stocker. Thanks to the Precipitation Processing System (PPS) team at NASA Goddard Space Flight Center, Greenbelt, Maryland, for data processing assistance.

\section{REFERENCES}

Andrews, E. D., R. C. Antweiler, P. J. Neiman, and F. M. Ralph, 2004: Influence of ENSO on flood frequency along the California coast. J. Climate, 17, 337-348, https://doi.org/10.1175/ 1520-0442(2004)017<0337:IOEOFF>2.0.CO;2.

Arkin, P. A., 1982: The relationship between interannual variability in the $200 \mathrm{mb}$ tropical wind field and the Southern Oscillation. Mon. Wea. Rev., 110, 1393-1404, https://doi.org/ 10.1175/1520-0493(1982)110<1393:TRBIVI > 2.0.CO;2.

Ashok, K., Z. Guan, and T. Yamagata, 2003: Influence of the Indian Ocean Dipole on the Australian winter rainfall. Geophys. Res. Lett., 30, 1821, https://doi.org/10.1029/2003GL017926.

Cayan, D. R., K. T. Redmond, and L. G. Riddle, 1999: ENSO and hydrologic extremes in the western United States. J. Climate, 12, 2881-2893, https://doi.org/10.1175/1520-0442(1999)012<2881: EAHEIT > 2.0.CO;2.

Cecil, D. J., and E. J. Zipser, 1999: Relationships between tropical cyclone intensity and satellite-based indicators of inner core convection: $85-\mathrm{GHz}$ ice-scattering signature and lightning. Mon. Wea. Rev., 127, 103-123, https://doi.org/10.1175/15200493(1999)127<0103:RBTCIA > 2.0.CO;2.

Dai, A., and T. M. L. Wigley, 2000: Global patterns of ENSO induced precipitation. Geophys. Res. Lett., 27, 1283-1286, https://doi.org/10.1029/1999GL011140.

Gershunov, A., 1998: ENSO influence on intraseasonal extreme rainfall and temperature frequencies in the contiguous United States: Implications for long-range predictability. J. Climate, 11, 3192-3203, https://doi.org/10.1175/1520-0442(1998)011<3192: EIOIER $>2.0 . \mathrm{CO} ; 2$.

Hamid, E. Y., Z.-I. Kawasaki, and R. Mardiana, 2001: Impact of the 1997-98 El Niño event on lightning activity over Indonesia. Geophys. Res. Lett., 28, 147-150, https://doi.org/10.1029/2000GL011374.

Hill, K. J., A. S. Taschetto, and M. H. England, 2011: Sensitivity of South American summer rainfall to tropical Pacific Ocean SST anomalies. Geophys. Res. Lett., 38, L01701, https:// doi.org/10.1029/2010GL045571.

Hou, A. Y., and Coauthors, 2014: The Global Precipitation Measurement mission. Bull. Amer. Meteor. Soc., 95, 701-722, https://doi.org/10.1175/BAMS-D-13-00164.1.

Iguchi, T., T. Kozu, R. Meneghini, J. Awaka, and K. Okamoto, 2000: Rain-profiling algorithm for the TRMM precipitation radar. J. Appl. Meteor., 39, 2038-2052, https://doi.org/10.1175/ 1520-0450(2001)040<2038:RPAFTT >2.0.CO;2.

—_ — J. Kwiatkowski, R. Meneghini, J. Awaka, and K. Okamoto, 2009: Uncertainties in the rain profiling algorithm for the TRMM precipitation radar. J. Meteor. Soc. Japan, 87A, 1-30, https://doi.org/10.2151/jmsj.87A.1.

Jong, B.-T., M. Ting, and R. Seager, 2016: El Niño impact on California precipitation: Seasonality, regionality, and El Niño intensity. Environ. Res. Lett., 11, 054021, https://doi.org/ 10.1088/1748-9326/11/5/054021.

Julian, P. R., and R. M. Chervin, 1978: A study of the Southern Oscillation and Walker Circulation phenomenon. Mon. Wea. Rev., 106, 1433-1451, https://doi.org/10.1175/1520-0493(1978) $106<1433$ :ASOTSO $>2.0 . \mathrm{CO} ; 2$.

Kiem, A. S., and S. W. Franks, 2001: On the identification of ENSO-induced rainfall and runoff variability: A comparison of methods and indices. Hydrol. Sci. J., 46, 715-727, https:// doi.org/10.1080/02626660109492866.

, and — 2004: Multidecadal variability of drought risk, eastern Australia. Hydrol. Processes, 18, 2039-2050, https:// doi.org/10.1002/hyp.1460. 
Kiladis, G. N., and H. F. Diaz, 1989: Global climate anomalies associated with extremes in the Southern Oscillation. J. Climate, 2, 1069-1090, https://doi.org/10.1175/1520-0442(1989)002<1069: GCAAWE $>2.0 . \mathrm{CO} ; 2$.

Kummerow, C., W. Barnes, T. Kozu, J. Shiue, and J. Simpson, 1998: The Tropical Rainfall Measuring Mission (TRMM) sensor package. J. Atmos. Oceanic Technol., 15, 809-817, https://doi.org/ 10.1175/1520-0426(1998)015<0809:TTRMMT>2.0.CO;2.

Laing, A. G., and J. G. Fritsch, 1997: The global population of mesoscale convective complexes. Quart. J. Roy. Meteor. Soc., 123, 389-405, https://doi.org/10.1002/qj.49712353807.

Leigh, R., and I. Kuhnel, 2001: Hailstorm loss modelling and risk assessment in the Sydney Region, Australia. Nat. Hazards, 24, 171-185, https://doi.org/10.1023/A:1011855801345.

Lindzen, R. S., and S. Nigam, 1987: On the role of sea surface temperature gradients in forcing low-level winds and convergence in the tropics. J. Atmos. Sci., 44, 2418-2436, https://doi.org/10.1175/ 1520-0469(1987)044<2418:OTROSS $>2.0$. CO 2 .

Liu, C., and E. J. Zipser, 2005: Global distribution of convection penetrating the tropical tropopause. J. Geophys. Res., 110, D23104, https://doi.org/10.1029/2005JD006063.

— and _ 2015: The global distribution of largest, deepest, and most intense precipitation systems. Geophys. Res. Lett., 42, 3591-3595. https://doi.org/10.1002/2015GL063776.

,$- \ldots$, and S. W. Nesbitt, 2007: Global distribution of tropical deep convection: different perspectives from TRMM infrared and radar data. J. Climate, 20, 489-503, https://doi.org/10.1175/ JCLI4023.1.

$\longrightarrow,-$ D. J. Cecil, S. W. Nesbitt, and S. Sherwood, 2008: A cloud and precipitation feature database from nine years of TRMM observations. J. Appl. Meteor. Climatol., 47, 27122728, https://doi.org/10.1175/2008JAMC1890.1.

Liu, N., and C. Liu, 2016: Global distribution of deep convection reaching tropopause in 1 year GPM observations. J. Geophys. Res. Atmos., 121, 3824-3842, https://doi.org/10.1002/ 2015JD024430.

$\longrightarrow$, and - 2018: Synoptic environments and characteristics of convection reaching the tropopause over northeast China. Mon. Wea. Rev., 146, 745-759, https://doi.org/10.1175/MWR-D-17-0245.1.

Lyon, B., and A. G. Barnston, 2005: ENSO and the spatial extent of interannual precipitation extremes in tropical land areas. J. Climate, 18, 5095-5109, https://doi.org/10.1175/JCLI3598.1.

Mapes, B. E., and R. A. Houze, 1993: Cloud clusters and superclusters over the oceanic warm pool. Mon. Wea. Rev., 121, 1398-1416, https://doi.org/10.1175/1520-0493(1993)121<1398: CCASOT $>2.0 . \mathrm{CO} ; 2$.

McBride, J. L., and N. Nicholls, 1983: Seasonal relationships between Australian rainfall and the Southern Oscillation. Mon. Wea. Rev., 111, 1998-2004, https://doi.org/10.1175/15200493(1983)111<1998:SRBARA > 2.0.CO;2.

Meyers, G., P. McIntosh, L. Pigot, and M. Pook, 2007: The years of El Niño, La Niña, and interactions with the tropical Indian Ocean. J. Climate, 20, 2872-2880, https://doi.org/10.1175/JCLI4152.1.

Mohr, K. I., and E. J. Zipser, 1996: Mesoscale convective systems defined by their $85-\mathrm{GHz}$ ice scattering signature: Size and intensity comparison over tropical oceans and continents. Mon. Wea. Rev., 124, 2417-2437, https://doi.org/10.1175/15200493(1996)124<2417:MCSDBT>2.0.CO;2.

_ J. S. Famiglietti, and E. J. Zipser, 1999: The contribution to tropical rainfall with respect to convective system type, size, and intensity estimated from the $85-\mathrm{GHz}$ ice-scattering signature. J. Appl. Meteor., 38, 596-606, https://doi.org/10.1175/ 1520-0450(1999)038<0596:TCTTRW > 2.0.CO;2.
—, J. Molinari, and C. D. Thorncroft, 2009: The interannual stability of cumulative frequency distributions for convective system size and intensity. J. Climate, 22, 5218-5231, https:// doi.org/10.1175/2009JCLI2940.1.

Nesbitt, S. W., and E. J. Zipser, 2000: A census of precipitation features in the tropics using TRMM: Radar, ice scattering, and lightning observations. J. Climate, 13, 4087-4106, https://doi.org/10.1175/ 1520-0442(2000)013<4087:ACOPFI > 2.0.CO;2.

— and _ 2003: The diurnal cycle of rainfall and convective intensity according to three years of TRMM measurements. J. Climate, 16, 1456-1475, https://doi.org/10.1175/1520-044216.10.1456.

,-- , and D. J. Cecil, 2000: A census of precipitation features in the tropics using TRMM: Radar, ice scattering, and lightning observations. J. Climate, 13, 4087-4106, https://doi.org/ 10.1175/1520-0442(2000)013<4087:ACOPFI > 2.0.CO;2.

- R. Cifelli, and S. A. Rutledge, 2006: Storm morphology and rainfall characteristics of TRMM precipitation features. Mon. Wea. Rev., 134, 2702-2721, https://doi.org/10.1175/MWR3200.1.

Power, S. B., F. Tseitkin, S. Torok, B. Lavery, R. Dahni, and B. McAvaney, 1998: Australian temperature, Australian rainfall and the Southern Oscillation, 1910-1992: Coherent variability and recent changes. Aust. Meteor. Mag., 47, 85-101.

Rasmusson, E. M., and T. H. Carpenter, 1982: Variations in tropical sea surface temperature and surface wind fields associated with the Southern Oscillation/El Niño. Mon. Wea. Rev., 110, 354-384, https://doi.org/10.1175/1520-0493(1982)110<0354: VITSST $>2.0 . \mathrm{CO} ; 2$.

— , and _ 1983: The relationship between eastern equatorial Pacific sea surface temperatures and rainfall over India and Sri Lanka. Mon. Wea. Rev., 111, 517-528, https://doi.org/10.1175/ 1520-0493(1983)111<0517:TRBEEP>2.0.CO;2.

Risbey, J. S., M. J. Pook, P. C. McIntosh, M. C. Wheeler, and H. H. Hendon, 2009: On the remote drivers of rainfall variability in Australia. Mon. Wea. Rev., 137, 3233-3253, https://doi.org/ 10.1175/2009MWR2861.1.

Romatschke, U., and R. A. Houze, 2010: Extreme summer convection in South America. J. Climate, 23, 3761-3791, https:// doi.org/10.1175/2010JCLI3465.1.

_ - S. Medina, and R. A. Houze, 2010: Regional, seasonal, and diurnal variations of extreme convection in the South Asian region. J. Climate, 23, 419-439, https://doi.org/10.1175/ 2009JCLI3140.1.

Ropelewski, C. F., and M. S. Halpert, 1986: North American precipitation and temperature patterns associated with the El Niño/Southern Oscillation (ENSO). Mon. Wea. Rev., 114, 2352-2362, https://doi.org/10.1175/1520-0493(1986)114<2352: NAPATP $>2.0 . \mathrm{CO} ; 2$.

$\longrightarrow$, and — 1987: Global and regional scale precipitation patterns associated with the El Niño-Southern Oscillation. Mon. Wea. Rev., 115, 1606-1626, https://doi.org/10.1175/15200493(1987)115<1606:GARSPP>2.0.CO;2.

Saji, H. N., B. N. Goswami, P. N. Vinayachandran, and T. Yamagata, 1999: A dipole mode in the tropical Indian Ocean. Nature, 401, 360-363.

Salio, P., M. Nicolini, and E. J. Zipser, 2007: Mesoscale convective systems over southeastern South America and their relationship with the South American low-level jet. Mon. Wea. Rev., 135, 1290-1309, https://doi.org/10.1175/MWR3305.1.

Shrestha, A., and R. Kostaschuk, 2005: El Niño/Southern Oscillation (ENSO)-related variablity in mean-monthly streamflow in Nepal. J. Hydrol., 308, 33-49, https://doi.org/10.1016/ j.jhydrol.2004.10.020. 
Spencer, R. W., H. M. Goodman, and R. E. Hood, 1989: Precipitation retrieval over land and ocean with the SSM/I: Identification and characteristics of the scattering signal. J. Atmos. Oceanic Technol., 6, 254-273, https://doi.org/10.1175/ 1520-0426(1989)006<0254:PROLAO > 2.0.CO;2.

Trenberth, K. E., G. W. Branstator, D. Karoly, A. Kumar, N.-C. Lau, and C. Ropelewski, 1998: Progress during TOGA in understanding and modeling global teleconnections associated with tropical sea surface temperatures. J. Geophys. Res., 103, $14291-$ 14324, https://doi.org/10.1029/97JC01444.

Walker, G. T., 1925: Correlation in seasonal variations of weather-A further study of world weather. Mon. Wea. Rev., 53, 252-254, https://doi.org/10.1175/1520-0493(1925)53<252: CISVOW $>2.0 . \mathrm{CO} ; 2$.

Wang, B., and H. Rui, 1990: Synoptic climatology of transient tropical intraseasonal convection anomalies: 1975-1985. Meteor. Atmos. Phys., 44, 43-61, https://doi.org/10.1007/BF01026810.

Webster, P. J., A. Moore, J. Loschnigg, and M. Leban, 1999: Coupled ocean-atmosphere dynamics in the Indian Ocean during 199798. Nature, 401, 356-360, https://doi.org/10.1038/43848.

Williams, E. R., 2005: Lightning and climate: A review. Atmos. Res., 76, 272-287, https://doi.org/10.1016/j.atmosres.2004.11.014.

Wolter, K., and M. S. Timlin, 2011: El Niño/Southern Oscillation behaviour since 1871 as diagnosed in an extended multivariate
ENSO index (MEI.ext). Int. J. Climatol., 31, 1074-1087, https://doi.org/10.1002/joc.2336.

Xie, S., K. Hu, J. Hafner, H. Tokinaga, Y. Du, G. Huang, and T. Sampe, 2009: Indian Ocean capacitor effect on Indo-Western Pacific climate during the summer following El Niño. J. Climate, 22, 730-747, https://doi.org/10.1175/2008JCLI2544.1.

Yang, X., and T. DelSole, 2012: Systematic comparison of ENSO teleconnection patterns between models and observations. J. Climate, 25, 425-446, https://doi.org/10.1175/JCLI-D-1100175.1.

Yeo, C. S., 2005: Severe thunderstorms in the Brisbane region and a relationship to the El Niño Southern Oscillation. Aust. Meteor. Mag., 54, 197-202.

Yuan, J., and R. A. Houze, 2010: Global variability of mesoscale convective system anvil structure from A-train satellite data. J. Climate, 23, 5864-5888, https://doi.org/10.1175/2010JCLI3671.1.

Zipser, E. J., D. J. Cecil, C. Liu, S. W. Nesbitt, and D. P. Yorty, 2006: Where are the most intense thunderstorms on Earth? Bull. Amer. Meteor. Soc., 87, 1057-1072, https://doi.org/ 10.1175/BAMS-87-8-1057.

Zolman, J. L., E. J. Zipser, and K. I. Mohr, 2000: A comparison of tropical mesoscale convective systems in El Niño and La Niña. J. Climate, 13, 3314-3326, https://doi.org/10.1175/1520-0442(2000) $013<3314$ :ACOTMC $>2.0$. CO 2 . 